\title{
Use of spironolactone to investigate the role of testosterone secretion during luteolysis in the goat
}

\author{
A. M. Homeida \\ Department of Veterinary Medicine, Pharmacology and Toxicology, University of Khartoum, \\ P.O. Box 32, Khartoum North, Sudan
}

\begin{abstract}
Summary. In non-pregnant goats, appreciable amounts of testosterone $(2 \cdot 1 \mathrm{ng} / \mathrm{g})$ and $5 \alpha$-dihydrotestosterone (DHT, $0.8 \mathrm{ng} / \mathrm{g}$ ) were present in the corpus luteum on Day 12 of the oestrous cycle. Significant $(P<0 \cdot 01, N=18)$ veno-arterial concentration differences of testosterone were found across ovaries bearing corpora lutea. No such difference in testosterone concentration occurred across ovaries without corpora lutea $(P>0.5, N=12)$. Increased peripheral plasma concentrations of testosterone and DHT occurred at the start of luteal regression, as monitored by progesterone concentration, and before the day of oestrus. Subcutaneous injections of spironolactone $(10 \mathrm{mg} / \mathrm{kg} / \mathrm{day})$ in peanut oil between Days 10 and 20 of the oestrous cycle inhibited the increase in testosterone and DHT concentrations and delayed luteolysis and oestrus. It is suggested that aromatization of testosterone to oestrogens is needed for luteal regression and expression of oestrus in goats.
\end{abstract}

\section{Introduction}

A marked rise in testosterone concentration around luteolysis has been demonstrated in nonpregnant cows and goats (Shemesh \& Hansel, 1974; Kanchev, Dobson, Ward \& Fitzpatrick, 1976; Kanchev \& Dobson, 1976; Homeida \& Cooke, 1984). The physiological importance of these peaks, which are similar in magnitude and timing in the two species, is not clear. However, exogenously administered testosterone will induce sexual behaviour and libido in female animals (Young, 1961; Katz, Oltenacu \& Foote, 1980; Homeida \& Cooke, 1984). In this study plasma concentrations of testosterone and $5 \alpha$-dihydrotestosterone (17 $\beta$-hydroxy-5 $\alpha$-androstan-3-one, DHT) were measured at the time of luteolysis and in the corpus luteum of non-pregnant goats. Spironolactone ( $7 \alpha-$ acetylthio-3-oxo-17 $\alpha$-pregn-4-ene-21,17 $\beta$-carbolactone), a diuretic and anti-androgenic substance (Steelman, Brooks, Morgan \& Patanelli, 1969), was administered during luteolysis in the goat to investigate the role of the rise in testosterone and DHT during this period since it is reported that spironolactone decreases the activity of the $17 \alpha$-hydroxylase and the content of cytochrome P-450 in the rat testis, resulting in an impairment in testosterone biosynthesis (Menard, Stripp \& Gillette, 1974).

\section{Materials and Methods}

Animals. Eighteen mature (2-3 years), female Nubian goats (weighing 20-22 kg) were used. They were housed in individual pens during the breeding season. After completion of one normal oestrous cycle (19-20 days), the goats were randomly divided into five groups. The treatment administered to each group was as follows.

Animals in Group $A(N=4$, controls) received daily subcutaneous injections of peanut oil $(3 \mathrm{ml})$ from Day 10 to Day 20 of the oestrous cycle (oestrus $=$ Day 0 ).

Animals in Group B $(\mathrm{N}=4)$ were treated exactly as Group A but with spironolactone 
(Boehringer, Mannheim, FRG) in peanut oil at a dose of $10 \mathrm{mg} / \mathrm{kg}$ body weight. This dose was selected because $5 \mathrm{mg} / \mathrm{kg} /$ day has no effect on testosterone secretion.

Animals in Group $\mathrm{C}(\mathrm{N}=4)$ were anaesthetized with halothane 12 days after oestrus and their corpora lutea were removed.

The 3 animals in Group D were anaesthetized with intravenous pentobarbitone sodium and anaesthesia was maintained with halothane in oxygen 11-13 days after oestrus. Polyvinyl catheters were inserted into an ovarian vein within $2 \mathrm{~cm}$ of the ovary and a uterine artery in each animal. Blood was collected every $30 \mathrm{~min}$ for $3 \mathrm{~h}$ and the plasma was stored until analysis.

Animals in Group E $(\mathrm{N}=3)$ were treated in the same way as those in Group D but on the day of oestrus.

In Groups A and B jugular blood $(5 \mathrm{ml})$ was collected twice daily by venepuncture using 23-gauge needles between Days 10 and 20 of the oestrous cycle. All blood samples were collected into heparinized nylon syringes, stored in ice for a short period and centrifuged at $1500 \mathrm{~g}$ for 10 min. Plasma samples were stored at $-30^{\circ} \mathrm{C}$ until analysis.

All females were checked for oestrus at least 3 times daily and considered to be in oestrus when they stood for mounting.

Hormone assay. All hormones were measured by specific radioimmunoassays (RIA).

Plasma progesterone was extracted in hexane and assayed using the method of Hotchkiss, Atkinson \& Knobil (1971). The antibody (provided by Dr H. Dobson) was raised in rabbits against progesterone-11-succinyl-BSA, and used at a final dilution of 1:7000; cross-reactions were $100 \%$ with progesterone and $<0.1 \%$ with corticosterone, desoxycorticosterone and 11 ketocorticosterone. The intra- and inter-assay coefficients of variation were $4.2 \%(n=15)$ and $12.5 \%(n=11)$, respectively, for a plasma sample of low progesterone concentration $(0.8 \mathrm{ng})$ and $4 \cdot 4 \%(n=15)$ and $12 \%(n=15)$, respectively, for a plasma sample of high concentration $(5 \mathrm{ng})$. The sensitivity of the assay was $48 \mathrm{pg} /$ tube. Extraction efficiency was $85.4 \pm 4.8$ (s.d.) $\%$ and the results were corrected for extraction losses.

Plasma testosterone and DHT were measured by RIA using the Amersham RIA Kit (Code TRK 600; Bucks, U.K.). Cross-reactions obtained were $100 \%$ for testosterone, $50 \%$ for DHT, $7 \%$ for androstanediol, and $<0.02 \%$ for progesterone and oestradiol- $17 \beta$. Plasma $(0.5 \mathrm{ml})$ was extracted with diethyl ether $(2 \times 3 \mathrm{ml})$ with vortex mixing. The ether layer was separated after snap-freezing the lower aqueous phase in acetone and solid $\mathrm{CO}_{2}$, and after evaporation the residue was dissolved in $1 \mathrm{ml}$ iso-octane (BDH Poole, U.K.) and applied to Celite (Sigma, St Louis, MO, U.S.A.) mini columns ( $5 \mathrm{~cm}$ Pasteur pipettes). The Celite in these columns was uniformly coated with a mixture of $20 \%$ water in propylene glycol (ratio of Celite:glycol mixture, $2: 1 \mathrm{w} / \mathrm{v}$ ) to form the celite matrix. These columns were equilibrated with $7 \mathrm{ml}$ iso-octane and eluted with $9 \mathrm{ml}$ to give the DHT fraction and then eluted with $6 \mathrm{ml}$ of $15 \%$ ethyl acetate in iso-octane to give the testosterone fraction (Abraham, Buster, Lucas, Corrales \& Teller, 1972). The solvent was evaporated and the residue dissolved in water for hormone assay. Efficiency of radioactive hormone recovery was $70 \pm 1 \cdot 8 \%(n=10)$ for testosterone and $76 \pm 2 \cdot 2 \%(n=12)$ for DHT and values were corrected for extraction and purification losses.

Buffer blanks were $9 \pm 1 \cdot 3 \mathrm{pg}(n=9)$ and $12 \pm 2 \mathrm{pg}(n=11)$ for testosterone and DHT, respectively. The intra-assay coefficients of variation were $12 \cdot 4 \%(n=10)$ and $10 \%(n=10)$ for a plasma sample with a low concentration of testosterone $(60 \mathrm{pg})$ and DHT (25 pg), respectively, and $12.6 \%(n=8)$ and $10.5 \%(n=10)$ for a sample with a high concentration of testosterone $(300 \mathrm{pg})$ and DHT (100 pg), respectively. The maximum binding was $53 \%$ of counts added at zero point on the standard curve and $15 \%$ and $24 \%$ with $100 \mathrm{pg}$ testosterone and DHT, respectively. Parallelism was determined by assaying $100 \mu \mathrm{l}$ which gave $83 \mathrm{pg}, 200 \mu \mathrm{l}(159 \mathrm{pg})$ and $400 \mu \mathrm{l}(311 \mathrm{pg})$ of pooled plasma taken on Day 13 of the oestrous cycle: for the testosterone assay $100 \mu$ l plasma gave a value of $83 \mathrm{pg}, 200 \mu \mathrm{l}$ gave $159 \mathrm{pg}$ and $400 \mu \mathrm{l}$ gave $311 \mathrm{pg}$, while for the DHT assay volumes of 100,200 and $400 \mu l$ gave values of 40,76 and $151 \mathrm{pg}$ respectively. 
For analysis of luteal content 5000 c.p.m. $\left[{ }^{3} \mathrm{H}\right]$ testosterone (sp. act. $98 \cdot 8 \mathrm{Ci} / \mathrm{mmol}$ ) were added to the tissues to calculate the efficiency of extraction ( 70 and $71 \%$ for testosterone and DHT, respectively). Tissue samples were homogenized in $5 \mathrm{ml} \mathrm{methanol} \mathrm{and} \mathrm{shaken} \mathrm{for} 1 \mathrm{~h}$ at $4^{\circ} \mathrm{C}$. The homogenate was centrifuged at $10000 \mathrm{~g}$ for $45 \mathrm{~min}$ at $4^{\circ} \mathrm{C}$. The supernatant was collected and taken to dryness under nitrogen (Shemesh, Hansel \& Concannon, 1975). The residue was extracted with diethyl ether and chromatographed on Celite columns as above.

Statistical analysis. The results were compared by Student's $t$ tests.

\section{Results}

The mean ( \pm s.d.) concentration of testosterone and DHT in the corpus luteum of non-pregnant goats (Group C) was $2.1 \pm 0.5 \mathrm{ng} / \mathrm{g}$ and $0.8 \pm 0.1 \mathrm{ng} / \mathrm{g}$ wet tissue, respectively. Significant $(P<0.01)$ veno-arterial concentration differences on testosterone were found for ovaries bearing corpora lutea (Group D); ovarian venous testosterone concentrations (mean \pm s.e.m., $3 \cdot 7 \pm 0 \cdot 3 \mathrm{ng} / \mathrm{ml}, n=18)$ exceeded arterial levels $(102 \pm 30 \mathrm{pg} / \mathrm{ml} ; n=18)$ in samples taken on Days 11,12 and 13 of the oestrous cycle. The progesterone concentration was $480 \pm 40 \mathrm{ng} / \mathrm{ml}$ and $50 \pm 10 \mathrm{ng} / \mathrm{ml}$ in the ovarian vein and uterine artery, respectively. In Group E, ovarian venous testosterone concentration $(0.4 \pm 0.1 \mathrm{ng} / \mathrm{ml}, n=12)$ was similar to that in the uterine artery $(0.38 \pm 0.1 \mathrm{ng} / \mathrm{ml} ; n=12)$. Progesterone concentration was 1.6 and $1 \cdot 1 \mathrm{ng} / \mathrm{ml}(n=10)$ in ovarian vein and uterine artery, respectively. The mean ( \pm s.d.) duration of the oestrous cycle in spironolactone-treated goats (Group B) was $23 \pm 0.44$ days and this was significantly $(P<0.01)$ longer than that of $19 \cdot 21 \pm 0.21$ days in the controls (Group A).

Table 1. Mean ( \pm s.d.) plasma concentrations of progesterone, testosterone and DHT at the time of luteolysis in goats treated with peanut oil (Group A) or spironolactone (Group B)

\begin{tabular}{|c|c|c|c|c|c|c|}
\hline \multirow{2}{*}{$\begin{array}{l}\text { Day of } \\
\text { oestrous } \\
\text { cycle }\end{array}$} & \multicolumn{2}{|c|}{ Progesterone $(\mathrm{ng} / \mathrm{ml})$} & \multicolumn{2}{|c|}{ Testosterone $(\mathrm{pg} / \mathrm{ml})$} & \multicolumn{2}{|c|}{$\mathrm{DHT}(\mathrm{pg} / \mathrm{ml})$} \\
\hline & Group A & Group B & Group A & Group B & Group A & Group B \\
\hline 10 & $4 \cdot 8 \pm 0 \cdot 3$ & $5 \cdot 1 \pm 0 \cdot 3$ & $65 \pm 16$ & $66 \pm 14$ & $40 \pm 10$ & $45 \pm 10$ \\
\hline 11 & $5.3 \pm 0.4$ & $5 \cdot 3 \pm 0.4$ & $68 \pm 18$ & $52 \pm 14$ & $38 \pm 10$ & $30 \pm 8$ \\
\hline 12 & $5 \cdot 1 \pm 0.5$ & $5.4 \pm 0.3$ & $90 \pm 15$ & $66 \pm 12$ & $50 \pm 12$ & $25 \pm 10$ \\
\hline 13 & $5 \cdot 3 \pm 0 \cdot 4$ & $5.3 \pm 0.4$ & $650 \pm 120$ & $80 \pm 14$ & $320 \pm 43$ & $20 \pm 8$ \\
\hline 14 & $4.3 \pm 0.3$ & $5 \cdot 1 \pm 0 \cdot 3$ & $320 \pm 50$ & $60 \pm 10$ & $108 \pm 22$ & $20 \pm 10$ \\
\hline 15 & $3 \cdot 5 \pm 0 \cdot 2$ & $4.9 \pm 0.4$ & $108 \pm 25$ & $35 \pm 14$ & $50 \pm 12$ & $25 \pm 8$ \\
\hline 16 & $2 \cdot 3 \pm 0.2$ & $4 \cdot 6 \pm 0.4$ & $80 \pm 12$ & $40 \pm 12$ & $38 \pm 12$ & $20 \pm 8$ \\
\hline 17 & $1 \cdot 4 \pm 0 \cdot 2$ & $4 \cdot 6 \pm 0 \cdot 3$ & $65 \pm 12$ & $32 \pm 10$ & $31 \pm 9$ & $20 \pm 7$ \\
\hline 18 & $0.4 \pm 0.2$ & $4 \cdot 8 \pm 0 \cdot 4$ & $51 \pm 11$ & $30 \pm 10$ & $26 \pm 18$ & $25 \pm 8$ \\
\hline 19 & $0 \cdot 2 \pm 0 \cdot 1$ & $4 \cdot 3 \pm 0 \cdot 3$ & $106 \pm 15$ & $32 \pm 12$ & $60 \pm 13$ & $20 \pm 8$ \\
\hline 20 & $0 \cdot 1 \pm 0 \cdot 1$ & $4 \cdot 6 \pm 0.4$ & $75 \pm 12$ & $30 \pm 10$ & $40 \pm 12$ & $25 \pm 9$ \\
\hline
\end{tabular}

In Group A goats luteolysis was characterized by a fall in progesterone concentration and a significant $(P<0.001)$ rise in testosterone on Days 13 and 14 of the oestrous cycle (baseline values $51-80 \mathrm{pg}$ testosterone $/ \mathrm{ml}$ and $22-50 \mathrm{pg}$ DHT $/ \mathrm{ml}$ ) (Table 1). Another peak of testosterone and DHT occurred before the day of oestrus.

In the goats treated with spironolactone (Group B) progesterone concentration did not decline but there was a significant $(P<0.01)$ decrease in testosterone and DHT values compared to Group A. 


\section{Discussion}

These results show that the goat corpus luteum on Day 12 of the oestrous cycle contains appreciable amounts of testosterone $(2 \cdot 1 \mathrm{ng} / \mathrm{g})$ and DHT $(0.8 \mathrm{ng} / \mathrm{g})$. The luteal content of testosterone is quantitatively similar to the amount present in the corpus luteum of the cow at the same time of the cycle (Shemesh et al., 1975). These results also show that the goat ovary secretes testosterone and that higher concentrations occur in blood draining the ovary bearing a corpus luteum. Ovarian secretion of testosterone has also been reported for women, ewes and cows (Short, 1962; McCracken, Baird \& Goding, 1971; Abraham, 1974; Kanchev et al., 1976; Wise, Caton, Thatcher, Rami Lehrer \& Fields, 1982). Testosterone is synthesized by the corpora lutea and ovarian follicles of the cow (Shemesh et al., 1975; Mori, 1975) and its presence, together with its metabolite DHT, in the corpus luteum and in the ovarian vein and peripheral blood in high amounts in the goat at the time of luteolysis suggests that the corpus luteum may be the source in this species and indicates a change in corpus luteum steroid metabolism. Shemesh et al. (1975) reported that addition of prostaglandin (PG) F-2 $\alpha$ to incubations of luteal tissue of cows stimulated testosterone synthesis. This may also occur during luteal regression of the goat because testosterone and PGF-2 $\alpha$ are released on Days 13 and 14 of the cycle (Homeida \& Cooke, 1982, 1984; Cooke \& Homeida, 1984). It is possible that testosterone, by acting as a precursor in the synthesis of oestrogens via the aromatizing pathway (Ainsworth \& Kennet, 1966; Massa \& Martini, 1974), helps in the secretion of PGF-2 $\alpha$ (Sharma \& Fitzpatrick, 1974).

Spironolactone, an anti-mineralocorticoid and anti-androgenic substance (Kagawa, 1960; Steelman et al., 1969), when given to goats after Day 10 of the oestrous cycle completely inhibited the release of testosterone and maintained luteal progesterone production. This suggests that testosterone may be needed for luteal regression as well as for the expression of oestrous behaviour. Inhibition of testosterone production by spironolactone may result in the removal of the source of oestrogens needed for secretion of PGF-2 $\alpha$, the uterine luteolysin. However, spironolactone has been shown to stimulate the release of luteinizing hormone and increase plasma concentrations of progesterone in several species (Rose, Underwood, Newmark, Kisch \& Williams, 1977; Baba, Murai, Jitsukawa, Hata \& Tazak, 1978), an effect which may have contributed to the maintenance of corpus luteum function.

I thank Dr H. Dobson, University of Liverpool, for the gift of progesterone antiserum and Khartoum Faculty of Veterinary Science for financial support.

\section{References}

Abraham, G.E. (1974) Ovarian and adrenal contribution to peripheral androgens during menstrual cycle. $J$. clin. Endocr. Metab. 39, 340-347.

Abraham, G.E., Buster, J.E., Lucas, L.A., Corrales, P.C. \& Teller, R.C. (1972) Chromatographic separation of steroid hormones for use in radioimmunoassay. Analytical Letters 5, 509-517.

Ainsworth, L. \& Kennet, J.R. (1966) Steroid hormone transformations by endocrine organs from pregnant mammals. I. Estrogen biosynthesis by mammalian placental preparations in vitro. Endocrinology 79, 875-883.

Baba, S., Murai, M., Jitsukawa, S., Hata, M. \& Tazaki, H. (1978) Antiandrogenic effects of spironolactone: hormonal and ultrastructural studies in dogs and men. J. Urol. 119, 375 380 .
Cooke, R.G. \& Homeida, A.M. (1984) Delayed luteolysis and suppression of the pulsatile release of oxytocin after indomethacin treatment in the goat. Res. Vet. Sci. 36, 48-51.

Homeida, A.M. \& Cooke, R.G. (1982) Peripheral plasma concentration of 13,14-dihydro-15-keto prostaglan$\operatorname{din} \mathrm{F}_{2 u}$ and progesterone around luteolysis and during early pregnancy in the goat. Prostaglandins 24, 313-321.

Homeida, A.M. \& Cooke, R.G. (1984) Plasma concentrations of testosterone and $5 \alpha$-dihydrotestosterone around luteolysis in goats and their behavioural effects after ovariectomy. J. Steroid Biochem. 20, 1357-1359.

Hotchkiss, J., Atkinson, L.E. \& Knobil, E. (1971) Time course of serum estrogen and luteinizing hormone 
(LH) concentrations during the menstrual cycle of the Rhesus monkey. Endocrinology 89, 177-183.

Kagawa, C.M. (1960) Blocking the renal electrolyte effects of mineralocorticoids with an orally active steroidal spironolactone. Endocrinology 67, 125-132.

Kanchev, L.N. \& Dobson, H. (1976) Plasma concentration of andostenedione during the bovine oestrous cycle. J. Endocr. 71, 351-354.

Kanchev, L.N., Dobson, H., Ward, W.R. \& Fitzpatrick, R.J. (1976) Concentrations of steroids in bovine peripheral plasma during the oestrous cycle and effects of betamethasone treatment. $J$. Reprod. Fert. 48, 341-345.

Katz, L.S., Oltenacu, E.A.B. \& Foote, R.H. (1980) The behavioural responses in ovariectomized cattle to either estradiol, testosterone, androstenedione, or dihydrotestosterone. Horm. \& Behav. 14, 224-235.

Massa, R. \& Martini, L. (1974) Testosterone metabolism: a necessary step for activity? J. Steroid Biochem. 5, 941-947.

McCracken, J.A., Baird, D.T. \& Goding, J.R. (1971) Factors affecting the secretion of steroids from the transplanted ovary in the sheep. Recent Prog. Horm. Res. 27, 537-582.

Menard, R.H., Stripp, B. \& Gillette, J.R. (1974) Spironolactone and testosterone cytochrome P-450: decreased testosterone formation in several species and changes in hepatic drug metabolism. Endocrinology 94, 1628-1636.

Mori, T. (1975) Steroid hormone formation in bovine ovarian follicles. Endocr. jap. 22, 361-366.
Rose, L.I., Underwood, R.H., Newmark, S.R., Kisch, E.S. \& Williams, G. (1977) Pathophysiology of spironolactone induced gynecomastia. Ann. intern. Med. 87, $398-403$.

Sharma, S.C. \& Fitzpatrick, R.J. (1974) Effect of oestradiol $17 \beta$ and oxytocin treatment on prostaglandin F Alph release in the anoestrous ewe. Prostaglandins 6, 97-101.

Shemesh, M. \& Hansel, W. (1974) Measurement of bovine plasma testosterone by radioimmunoassay (RIA) and by a rapid competitive protein binding (CPB) assay. J. Anim. Sci. 39, 720-724.

Shemesh, M., Hansel, W. \& Concannon, P.W. (1975) Testosterone synthesis in the bovine corpus luteum. Biol. Reprod. 13, 490-492.

Short, R.V. (1962) Steroids present in the follicular fluid of the cow. J. Endocr. 23, 401-411.

Steelman, S.L., Brooks, J.R., Morgan, E.R. \& Patanelli, D.J. (1969) Anti-androgenic activity of spironolactone. Steroids 14, 449450.

Young, W.C. (1961) Sex and Internal Secretions, p. 1196. Ed. W. C. Young. Williams and Wilkins, Baltimore.

Wise, T.H., Caton, D., Thatcher, W.W., Rami Lehrer, A. \& Fields, M.J. (1982) Androstenedione, dehydroepiandrosterone and testosterone in ovarian vein plasma and androstenedione in peripheral arterial plasma during the bovine oestrous cycle. J. Reprod. Fert. 66, 513-518.

Received 29 March 1985 